\title{
Anti-inflammatory and antiproliferative properties of sweet cherry phenolic-rich extracts
}

\author{
Ana C. Gonçalves ${ }^{1,2}$, Ana R. Costa ${ }^{1}$, José D. Flores-Félix ${ }^{1}$, Amílcar Falcão ${ }^{2,3}$, Gilberto Alves ${ }^{1}$, Luís R. Silva ${ }^{1,4^{*}}$ \\ 1 CICS-UBI - Health Sciences Research Centre, University of Beira Interior, Covilhã, Portugal; anacaro- \\ linagoncalves@sapo.pt (A.C.G.); anarfcosta1990@gmail.com (A.R.C.); jdflores@usal.es (J.D.F.-F.); gilber- \\ to@fcsaude.ubi.pt (G.A.) \\ 2 CIBIT - Coimbra Institute for Biomedical Imaging and Translational Research, University of Coimbra, \\ Coimbra, Portugal; acfalcao@ff.uc.pt \\ 3 Laboratory of Pharmacology, Faculty of Pharmacy, University of Coimbra, Coimbra, Portugal \\ 4 CPIRN-UDI/IPG, Center of Potential and Innovation of Natural Resources, Research Unit for Inland Devel- \\ opment (UDI), Polytechnic Institute of Guarda, Guarda, Portugal \\ * Correspondence: luisfarmacognosia@gmail.com; Tel.: +351-275-329-077
}

\begin{abstract}
Cherries have been largely investigated due to their high content in phenolics in order to fully explore their health-promoting properties. Therefore, this work aimed to assess, for the first time, the anti-inflammatory potential of phenolic-targeted fractions of Saco cherry, using RAW 264.7 macrophages stimulated with lipopolysaccharide. Additionally, the cytotoxic effects on gastric adenocarcinoma (AGS), neuroblastoma (SH-SY5Y) and normal human dermal fibroblast (NHDF) cells were evaluated, as well as the ability to protect these cellular models against induced oxidative stress. The obtained data revealed that cherry fractions can interfere with cellular nitric oxide (NO) levels by capturing NO radicals and decreasing inducible nitric oxide synthase and cyclooxygenase-2 expression. Furthermore, it was observed that all cherry fractions exhibited dose-dependent cytotoxicity against AGS cells, presenting cytotoxic selectivity for these cancer cells when compared to SH-SY5Y and NHDF cells. Regarding their capacity to protect cancer cells against oxidative injury, in most assays, the total cherry extract was the most effective. Overall, this study reinforces the sweet cherries incorporation in new pharmaceutical products, smart foods and nutraceuticals.
\end{abstract}

Keywords: anti-inflammatory; cytotoxicity; oxidative stress; phenolic compounds; sweet cherries.

\section{Introduction}

Over the past few years, research related to multi-target active compounds, particularly those extracted from natural products, has been largely explored, given their potential for treatment and/or prevention of several disorders [1]. In fact, and in accordance with the most recent reports, almost half of the drugs approved in the last 30 years derived from nature, mainly from medicinal plants [2]. Even so, and despite their use in traditional medicine, there is still a lack of knowledge about the full biological potential, medicinal value and chemical profile of most natural products.

The genus Prunus is distributed worldwide, and includes approximately 430 species; among such species, Prunus avium, especially their fruits, known as sweet cherries, have been a target of exhaustive studies [3-8]. Since ancient times, their vegetal parts are used in traditional medicine as diuretics, sedatives, draining and anti-inflammatory agents $[9,10]$. Supported by scientific evidence, their consumption and economic value are rising worldwide, mostly due to their potential therapeutic properties [11]. These are closely linked to their high content in phenolic compounds, which already showed potential to counteract oxidative stress and inflammatory conditions [5,9,11-15]. Taking into account that the inflammation is considered a mechanism of protection against infection or injury, the overexpression of pro-inflammatory enzymes, together with an unbalanced produc- 
tion of free radicals and reactive species, like nitric oxide $(\bullet \mathrm{NO})$ and hydrogen peroxide $\left(\mathrm{H}_{2} \mathrm{O}_{2}\right)$, induce cells' damage and apoptosis, contributing for the development of many chronic inflammatory disorders (e.g., diabetes, obesity and rheumatoid arthritis) [16,17].

Nowadays, it is already accepted that the daily ingestion of phenolic-rich sources is an effective approach to suppress these events, given their capacity to act as antioxidant species, modulate arachidonic acid metabolism (e.g., cyclooxygenase (COX), lipoxygenases and phospholipase A2), interact with pro-inflammatory nuclear factor $\kappa \mathrm{B}$, decrease the expression of inducible nitric oxide synthase (iNOS), and thus, promote a healthy state [18-22].

Bearing these facts in mind and considering previous studies from our research group, which showed that sweet cherry phenolics possess notable antioxidant and $\alpha$-glucosidase inhibitory effects and capacity to interfere with human colorectal adenocarcinoma and hepatic cells growth [4,5], we considered it relevant to study, for the first time, the effects of these active metabolites on • NO levels in LPS-stimulated RAW 264.7 macrophages. For this purpose, there were prepared three enriched fractions in phenolics extracted from sweet cherries (cv. Saco): one rich in coloured phenolics (coloured fraction, another one rich in non-coloured phenolics (non-coloured fraction) and a third one rich in both coloured and non-coloured phenolics (total extract). Additionally, the cytotoxic potential of each fraction against two human cancer cell lines, namely gastric adenocarcinoma (AGS) and neuroblastoma (SH-SY5Y) and possible mechanisms of action involved were also investigated, as well as their protective effects after exposure to tert-butyl hydroperoxide ( $t$ - $\mathrm{BHP}), \mathrm{H}_{2} \mathrm{O}_{2}$, and glutamate. For comparative purposes, we also tested the effects of each fraction on the viability of normal human dermal fibroblast (NHDF) cells.

\section{Results and Discussion}

\subsection{Anti-inflammatory activity}

Inflammation is a physiological response of the human body that aims to eliminate, neutralize and/or destroy stimuli resulting from microbial infection or tissue injury [18]. However, when it occurs exaggeratedly, it may become dangerous for host tissues, and be a precursor of many disorders, including cancer and neurological pathologies [23,24]. In this context, proinflammatory COX enzymes convert arachidonic acid to prostaglandins, and higher amounts of tumor necrosis factor (TNF)- $a$, interleukin (IL)- 6 and $\bullet N O$, which are originated from oxygen and L-arginine by inducible nitric oxide synthase (iNOS) $[18,25,26]$. Furthermore, several efforts have been done in the research of effective compounds to inhibit iNOS, COX-2 and related pathways, with or without low side effects, in order to prevent the occurrence of chronic disorders. Knowing that many phenolics had already shown to be promising therapeutic approaches [12,24,27-29], we decided to evaluate the anti-inflammatory potential of the phenolic-targeted fractions from sweet cherries.

\subsubsection{Effect of sweet cherry fractions on RAW 264.7 macrophages viability}

In order to exclude the possibility that the cytotoxicity of phenolic-targeted fractions might contribute to their anti-inflammatory effects on RAW 264.7 cells, preliminary experiments were conducted to assess the range of concentrations for which the exposure to each fraction did not significantly affect cell viability (Fig. 1A). Through MTT and LDH leakage assays, it was possible to see those concentrations ranging from 50 to $800 \mu \mathrm{g} / \mathrm{mL}$ did not affect cells' viability, and hence, these were chosen for the subsequent experiments. 

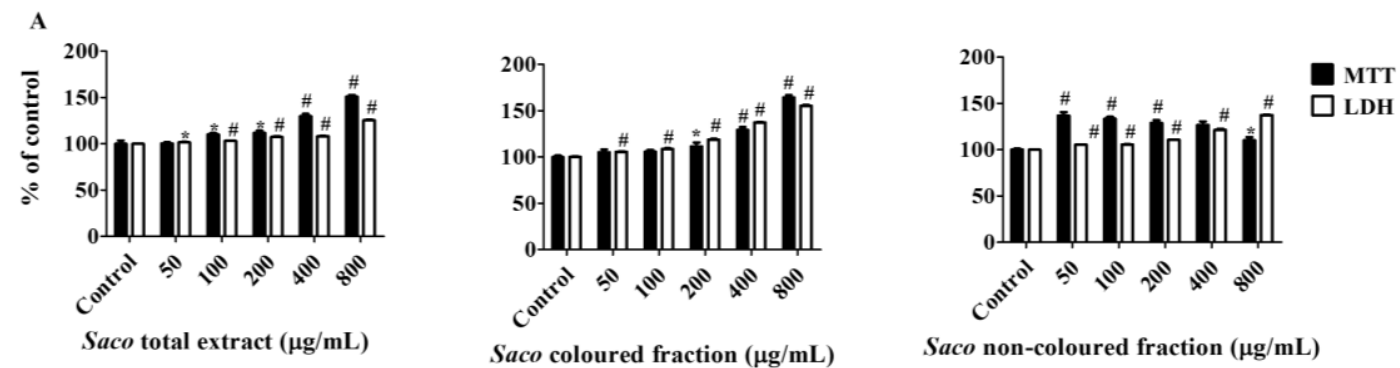

B
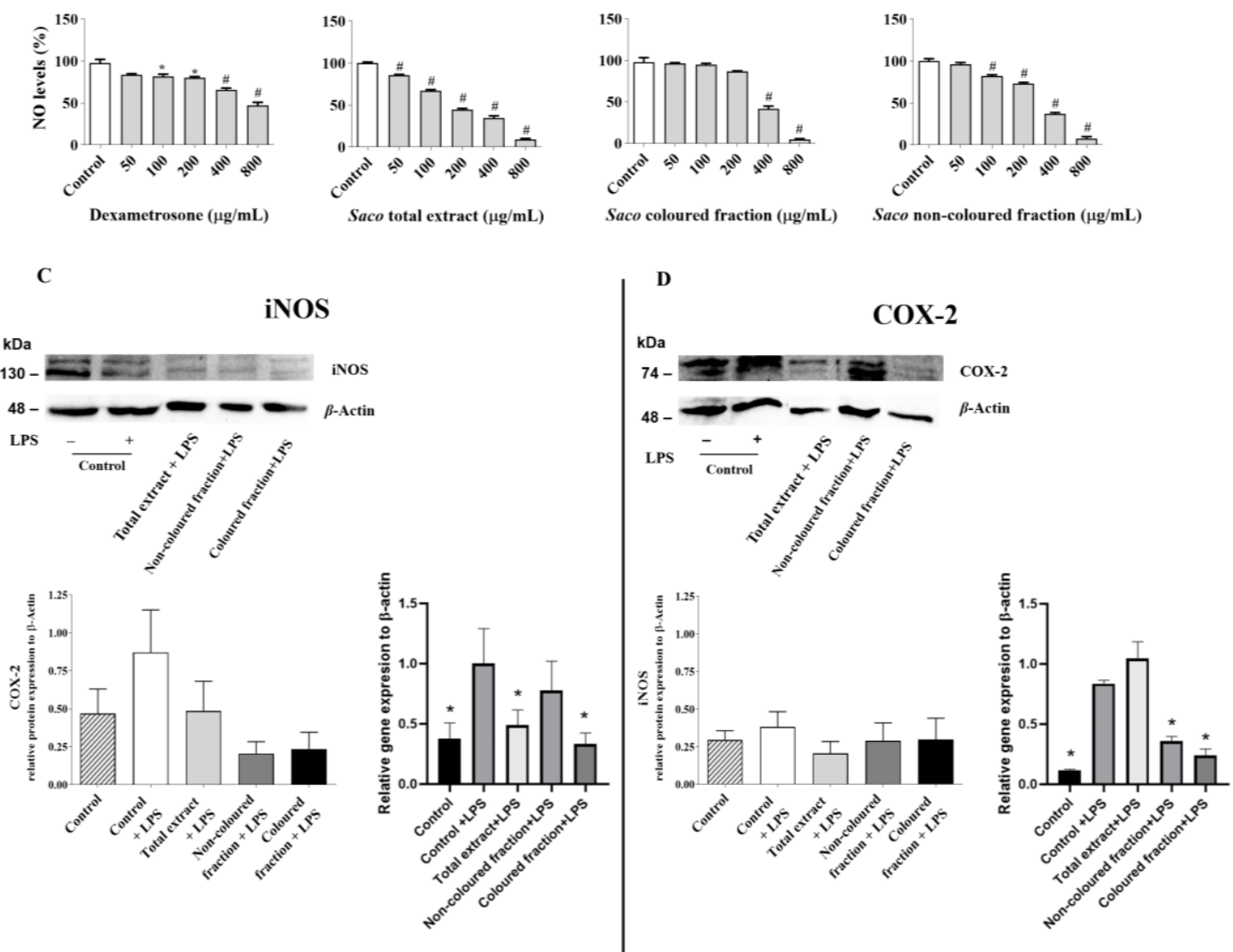

Figure 1. (A) Effect of sweet cherry fractions on RAW 264.7 macrophages, evaluated by 3-(4,5-dimethylthiazol-2-yl)-2,5-diphenyltetrazolium bromide (MTT) reduction and lactate dehydrogenase leakage (LDH) assays. (B) Effect in nitric oxide levels of cells pre-treated for 2 hours with cherry fractions and cherry extract, followed by 22 hours co-treatment with $1 \mu \mathrm{g} / \mathrm{mL}$ of lipopolysaccharide (LPS). (C) Effect of cherry fractions and cherry extract on LPS-induced iNOS and (D) COX-2 expression. $\beta$-actin was used as an internal control for Western blot and qPCR analysis. Results are expressed as mean \pm SEM of, at least, six independent experiments, performed in triplicate. ${ }^{*} \mathrm{P}<0.05,{ }^{* *} \mathrm{p}<$ 0.01 and ${ }^{\sharp} P<0.0001$.

\subsubsection{Effect of sweet cherry fractions on $\bullet N O$ levels in cell culture medium}

Considering the previously selected concentrations, the possible capacity of each fraction to initiate an immune response, when in the presence of invaders, by decreasing -NO concentrations in the culture medium of LPS-challenged macrophages was evaluated (measured as nitrite formation). The bacterial LPS was used to induce inflammation in these cells, and consequently to promote the formation of several inflammatory mediators, including $\cdot \mathrm{NO}$ and COX-2. Therefore, after 22 hours of concomitant exposure to LPS and each fraction from sweet cherries, it was possible to observe a significant concentration-dependent reduction on $\cdot \mathrm{NO}$ levels, suggesting anti-inflammatory effects 
(Figure 1B). Statistical differences were found between fractions. The total extract was the most effective to scavenging $\cdot \mathrm{NO}\left(\mathrm{IC}_{50}=176.29 \pm 1.39 \mu \mathrm{g} / \mathrm{mL}\right)$, followed by the coloured and non-coloured fractions (IC50 values of $338.31 \pm 1.52$ and $367.93 \pm 2.10 \mu \mathrm{g} / \mathrm{mL}$, respectively). All of them were most effective than the positive control dexamethasone (IC $50=$ $593.64 \pm 2.37 \mu \mathrm{g} / \mathrm{mL})$.

The obtained data is in agreement with other studies also focused on the potential of phenolic-rich fractions to reduce $\bullet \mathrm{NO}$ levels in culture medium $[4,14,26,30]$. Furthermore, it was also possible to verify that the combination of coloured and non-coloured phenolic compounds in total extract act synergistically to enhance anti-inflammatory potential. Among phenolics present in cherries, quercetin, $\rho$-coumaric and ferulic acids (at $20 \mu \mathrm{M})$, quercetin and kaempferol (at $100 \mu \mathrm{M}$ ), and cyanidin 3-O-rutinoside (at $33 \mu \mathrm{M}$ ) already showed potential to scavenge $\cdot \mathrm{NO}$ produced by LPS-stimulated RAW 264.7 cells [27-29,31]. In order to understand if the obtained results can be intimately associated with the capacity of phenolic-targeted fractions to modulate iNOS and/or COX-2, and/or to their antioxidant capacity to scavenge $\bullet \mathrm{NO}$, more studies were performed.

\subsubsection{Effect of sweet cherry fractions on LPS-induced iNOS and COX-2 expression}

Therefore, to profound the results and knowing that iNOS and COX-2 are two critical enzymes to exacerbate inflammation, being both the main responsible to synthesize $\mathrm{NO}$ and prostaglandins, respectively, we decided to check the capacity of phenolic-target fractions to modulate their expression, by Western blot analysis and qPCR. For that, we used protein extracts from cells treated with cherry fractions at $200 \mu \mathrm{g} / \mathrm{mL}$ (coloured fraction) and $400 \mu \mathrm{g} / \mathrm{mL}$ (total extract and non-coloured fraction), which corresponded approximately to almost half of $\bullet \mathrm{NO}$ inhibition. As observed in Figure 1C-D, the incubation of RAW cells under LPS seems to enhance COX-2 and iNOS expression when compared to untreated cells (negative control). In addition, the treatment with phenolic-target fractions seems to slightly decrease both expression levels, when compared to cells only exposed to LPS alone. Regarding iNOS, the total extract and coloured fraction seemed to be the most effective, while, in COX-2, it was the coloured and non-coloured fraction. Although no statistically significant results were observed in Western blot assay, significant data was obtained in qPCR assay considering the total extract and coloured fraction for iNOS, and coloured and non-coloured fractions for COX-2. Similar differences between RNA expression though qPCR and protein detection by Western blot have been reported in other works that employed LPS as proinflammatory factor, being the vestigial increments observed in COX-2 mRNA expression after total extract treatment considered predictable and related with its role in mediating prostaglandins' synthesis verified in the early stages of inflammation [30,32,33]. Additionally, and given the obtained data, it is expectable this modulation occurs in a concentration-dependent manner and becomes more expressive over time.

The anti-inflammatory effects of sweet cherries are known. For example, Jacob and colleagues [34] already referred that the daily consumption of $280 \mathrm{~g}$ of cherries by healthy women can lower plasma C-reactive protein and NO concentrations, 3 hours after intake. Additionally, Delgado and collaborators [35] also mentioned the capacity of sweet cherry fruits to down-regulate the levels of IL- $1 \beta$ and TNF- $\alpha$ pro-inflammatory cytokines and increase IL-4 and IL-2 anti-inflammatory cytokines in rats that consumed $141 \mathrm{~g}$ fresh cherries for 10 days.

Inevitably, the anti-inflammatory capacity showed by these fruits is closely attributed to the presence of anthocyanins. In fact, anthocyanins extracted from cherries already showed a stronger ability to inhibit COX-2 at a concentration of $125 \mu \mathrm{g} / \mathrm{mL}$ (47.4\% of inhibition) than ibuprofen $(39.8 \%)$ and naproxen $(41.3 \%)$ [36]. This modulation is due to the capacity of phenolics to down-regulate nuclear factor-kappa B (NF- $\kappa \mathrm{B})$, affecting the biosynthesis of iNOS and COX-2, and consequently reducing the formation of $\mathrm{NO}$ and prostaglandins, respectively, and suppressing mitogen-activated protein kinases (MAPKs) and JNK1/2 phosphorylation [37,38]. Besides the anthocyanins, other phenolics present in cherries also showed ability to interfere with inflammatory-related pathways 
and to reduce pro-inflammatory markers, including hydroxybenzoic acids $(25 \mu \mathrm{M})$, caffeic acid $(10 \mu \mathrm{M}), \rho$-coumaric acid $(50 \mu \mathrm{M})$ and quercetin $(100 \mu \mathrm{M})[27,29,39-41]$.

\subsection{4. $\bullet$ NO scavenging activity}

Taking into account the in vitro results obtained with RAW 264.7 macrophages cells, we decided to assess if a process of direct ${ }^{-N O}$ scavenging occurs at the same time, contributing also to diminishing the $\cdot \mathrm{NO}$ levels in the culture medium. For this, a cell-free assay based on the photolytic decomposition of sodium nitroprusside was performed, using the same concentrations studied in cells. All the targeted fractions displayed significant scavenging activity in a concentration-dependent manner. The total extract and the coloured fractions were the most active, exhibiting NO reductions around $26 \%$, respectively, at the highest concentration tested $(800 \mu \mathrm{g} / \mathrm{mL}$ ) (IC50 values of $156.41 \pm 0.96$ and $167.29 \pm 0.96 \mu \mathrm{g} / \mathrm{mL}$, respectively) (Figure 2).

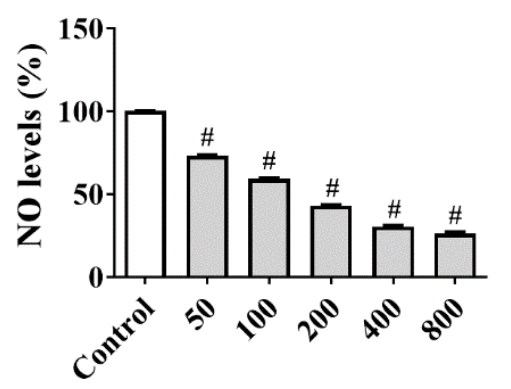

Saco total extract $(\mu \mathrm{g} / \mathrm{mL})$

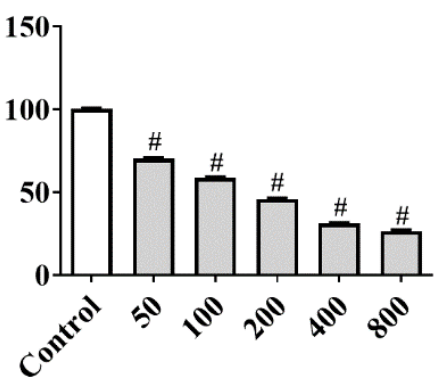

Saco coloured fraction $(\mu \mathrm{g} / \mathrm{mL})$

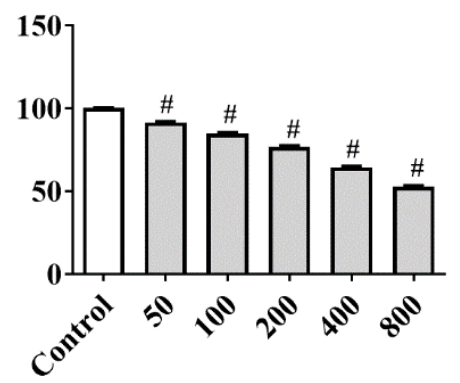

Saco non-coloured fraction $(\mu \mathrm{g} / \mathrm{mL})$

Figure 2. Antioxidant activity against nitric oxide radicals $(\cdot \mathrm{NO})$ of sweet cherry fractions in the cell-free assay. Data represent the mean \pm SEM of three independent experiments, performed in triplicate.

The obtained results are another support for the influence of the interaction of non-coloured phenolics with anthocyanins in the biological potential of sweet cherries. Overall, the results obtained suggest that the decrease of cellular $\cdot \mathrm{NO}$ levels is mainly due to the scavenger capacity of the extracts to scavenging $\bullet \mathrm{NO}$, and less by their capacity to decrease the expression of iNOS and COX-2.

3.2. Effect of sweet cherry fractions on the viability of human cancer cells

AGS and SH-SY5Y cell lines were selected given they are largely used as models of cellular response to xenobiotics and dopaminergic cells, respectively [42,43]. In this study, five different concentrations of each fraction (50,100, 200, 400 and $800 \mu \mathrm{g} / \mathrm{ml}$ ) were tested. The MTT assay demonstrated that AGS cells were more sensitive than SH-SY5Y and NHDF cells. In fact, there were verified significant decreases in cells viability, in a dose-dependent manner, when AGS cells were incubated with different concentrations of phenolic-targeted fractions from sweet cherries (Figure 3). 


\section{AGS cells}
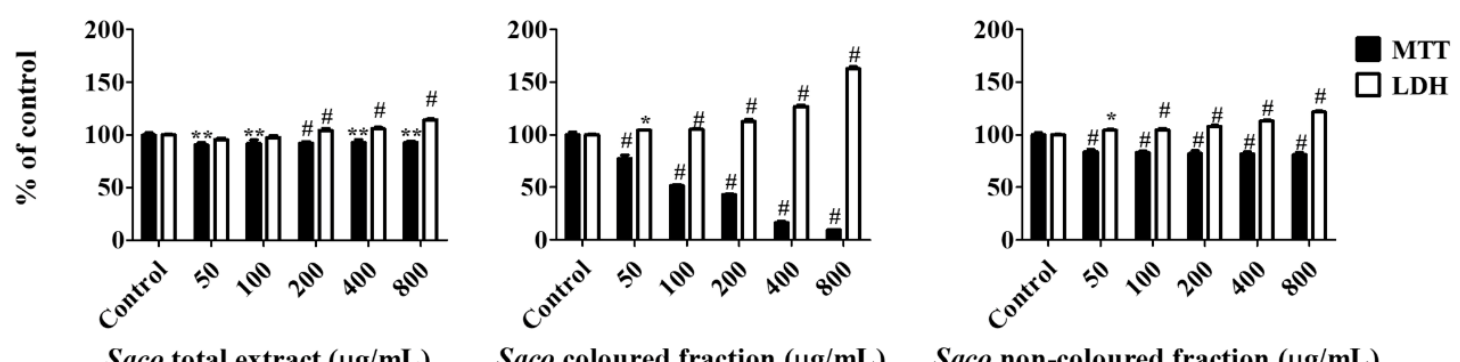

Saco coloured fraction $(\mu \mathrm{g} / \mathrm{mL})$

Saco non-coloured fraction $(\mu \mathrm{g} / \mathrm{mL})$

Figure 3. Effects of sweet cherry phenolic-targeted fractions on cellular viability of NHDF (A) and AGS (B) cells, assessed by 3-(4,5-dimethylthiazol-2-yl)-2,5-diphenyltetrazolium bromide (MTT) reduction and lactate dehydrogenase (LDH) leakage assays. Cells were treated with each fraction for 24 hours. Values show mean \pm SEM of six independent assays performed in triplicate compared to the respective control $\left({ }^{*} \mathrm{p}<0.05,{ }^{* *} \mathrm{p}<0.01\right.$ and $\# \mathrm{p}<0.0001)$.

The coloured fraction was the most effective in inducing DNA damage and cell death on AGS cells, revealing an IC 50 of $130.39 \pm 1.73 \mu \mathrm{g} / \mathrm{mL}$. On the other hand, no changes were verified on SH-S5Y5 nor on NHDF cells, which supports the cytotoxic selectivity of the fractions for AGS cells (data not shown). Moreover, and as expectable, the LDH response most notorious was also obtained in the highest tested concentrations of the coloured fraction, i.e., 200, 400 and $800 \mu \mathrm{g} / \mathrm{mL}$, showing values of $112.77,126.89$ and $163.05 \%$, respectively (Figure 3). Since MTT reduction results are more expressive than those of LDH in culture medium, it was also possible to conclude that mitochondrial activity losses happened before to membrane's damage, and therefore, the necrotic process only occurs in the highest concentrations tested $(400$ and $800 \mu \mathrm{g} / \mathrm{mL}$ ). This evidence is in agreement with other previous studies [5,43].

Noteworthy, the obtained data is directly linked to the capacity of phenolics to interact with the different cancer-related pathways, namely in arresting cells cycle, removing pre-carcinogen agents, regulating metastasis proteins, and inducing apoptosis. Additionally, phenolics can also reduce oxidative stress and stimulate DNA repair, and thus, blocking malignant transformation by promoting cellular differentiation and consequently, inhibiting the development and/or progression of the tumor. These abilities are strongly related to the chemical structure of these compounds, pointing to the carboxyl, hydroxyl, and methoxy groups, which confer them antioxidant and also pro-oxidant behaviors and anti-inflammatory actions, which in turn, increase their cytotoxicity effects on cancer cells.

Focusing on this work, the anticancer bioactivity of cherries is majority correlated with anthocyanins content, which is in accordance with previous studies $[5,44,45]$. In fact, the existence of multiple hydroxyl groups on their B ring enhances their biological potential. In agreement with that, it was already reported that phenolic-enriched fractions obtained from sweet cherries, underlining the anthocyanins-rich fraction, can efficiently interfere with human colon carcinoma Caco-2 cells, exhibiting an IC 50 of $667.84 \mu \mathrm{g} / \mathrm{mL}$ and a correlation between this activity and anthocyanins content of 0.6674 [5]. Even so, other non-coloured phenolics present in cherries, e.g., hydroxycinnamic acids, and quercetin derivatives also revealed anti-cancer effects on several human cancer cells, being this activity related to their antioxidative effects [46-48].

\subsubsection{Effect of sweet cherry fractions on the morphology of AGS cells}

Taking into account the obtained results, and in order to deepen the previous results, morphological and nuclear evaluation assays were also performed.

The observation of the cells after treatment under microscope revealed high amounts of debris (Figure 4), mainly in the highest concentrations $(800 \mu \mathrm{g} / \mathrm{mL})$ (Figure 
$4 \mathrm{H}-\mathrm{J})$, which can be considered another evidence about the toxicity effects of phenolic-targeted fractions on cancer cells.

\section{Control}

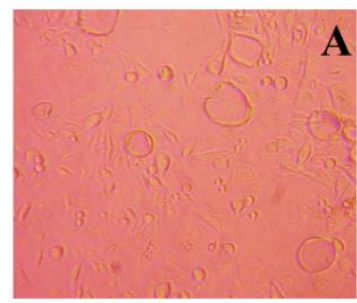

Saco total extract

Saco coloured fraction Saco non-coloured fraction
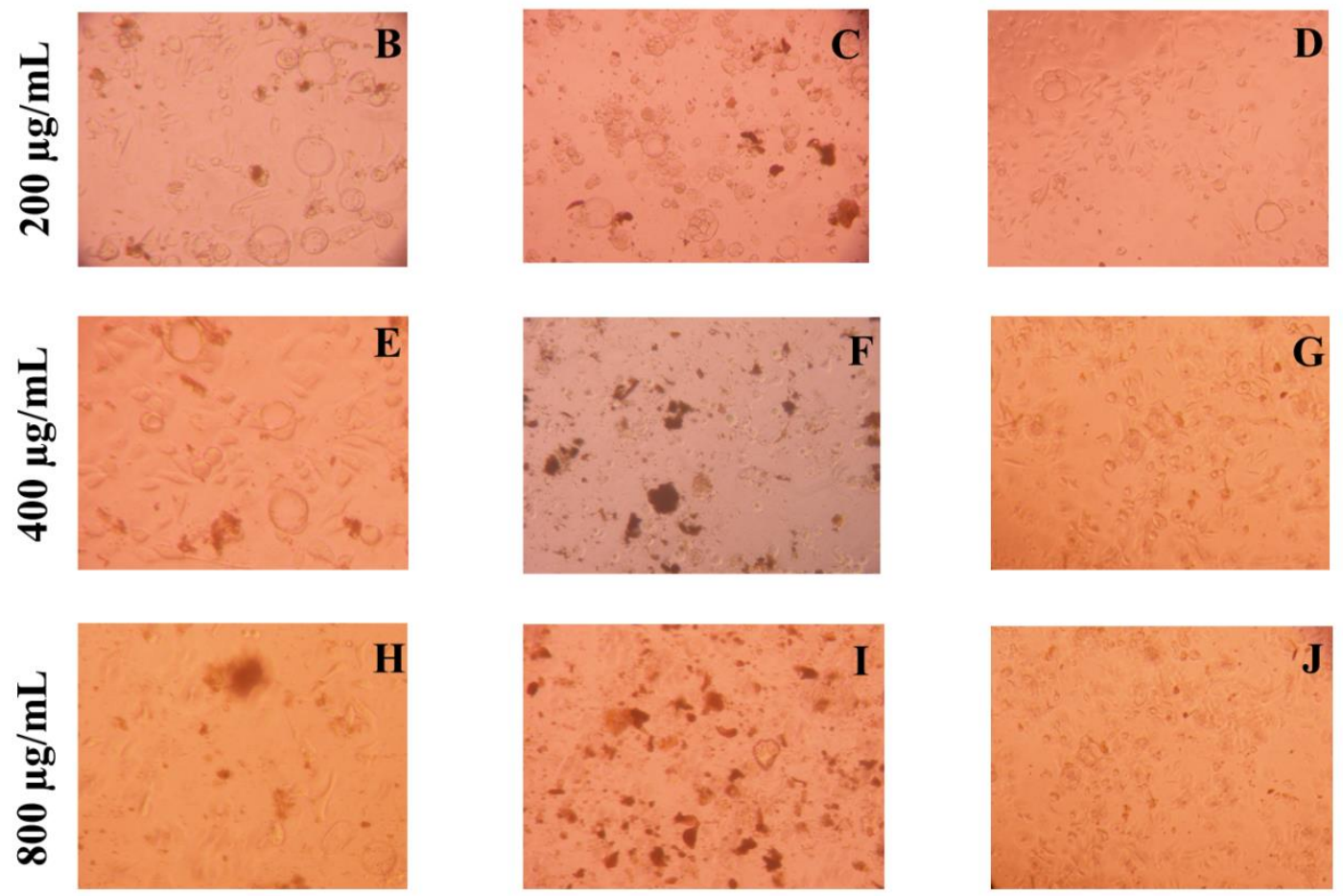

Figure 4. Effects of sweet cherry phenolic-targeted fractions on AGS cells morphology (control vs. treatment after 24 hours of incubation). (A) corresponds to the control, (B, E, $\mathrm{H})$ correspond to Saco total extract, while $(C, F, I)$ to the coloured fraction and (D, G, J) to the non-coloured one, at concentrations of 200, 400 and $800 \mu \mathrm{g} / \mathrm{mL}$, respectively. As expected, and considering the data of previous Figure, it was observed an increase in debris as the concentration of each fraction increased.

Furthermore, by nuclear staining, it was also possible to clearly observe the formation of cytoplasmatic blebs, followed by cells structure losses, nucleus condensation and vacuolization as the concentration of each fraction increases (Figure 5). 

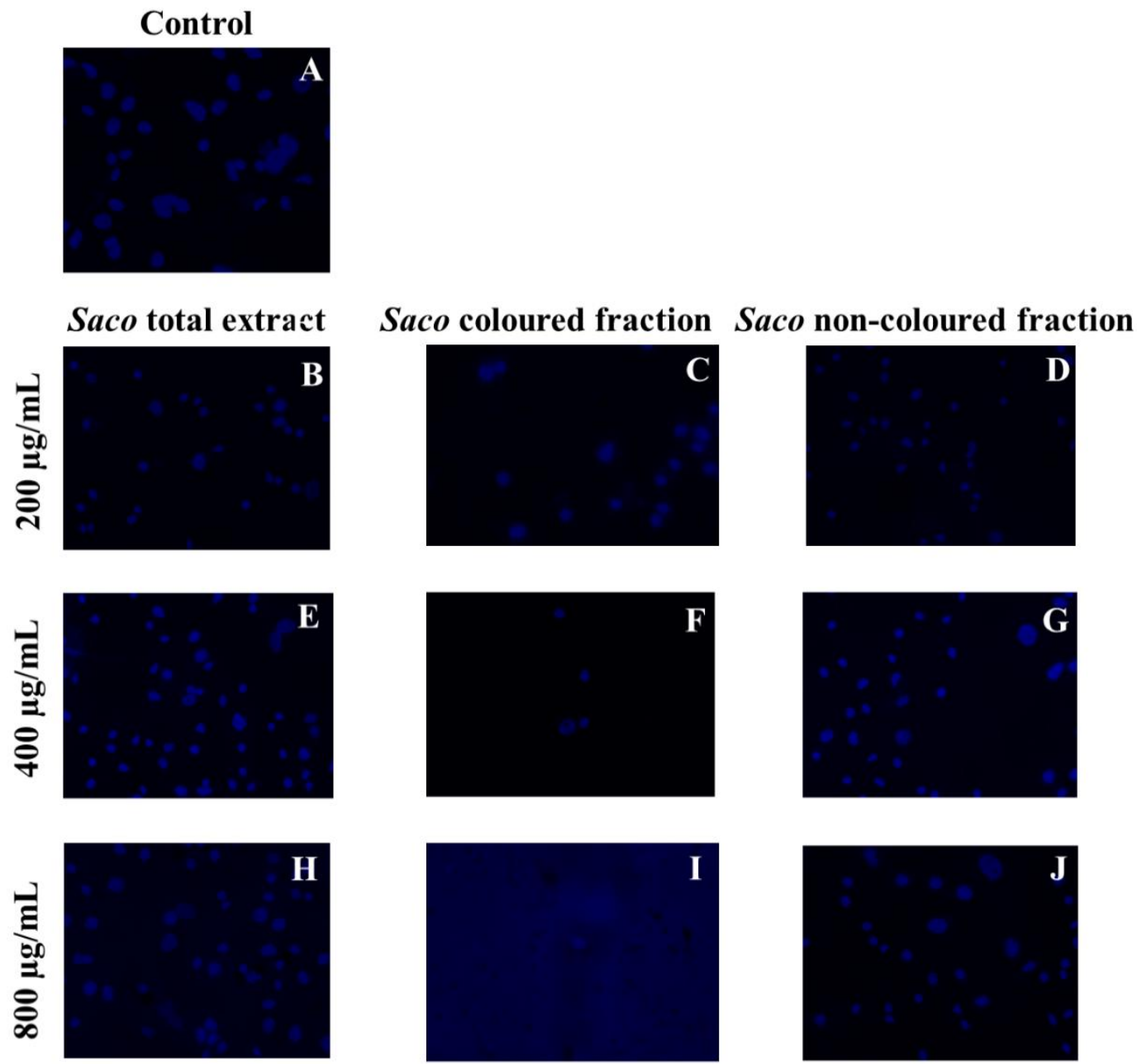

Figure 5. Effects of sweet cherry phenolic-targeted fractions on AGS cells' nucleus, visualized by 4',6-diamidine-2'-phenylindole dihydrochloride (control vs. treatment after $24 \mathrm{~h}$ of incubation). (A) corresponds to the control, (B, E, H) correspond to Saco total extract, while $(C, F, I)$ to the coloured fraction and (D, G, J) to the non-coloured one, at concentrations of 200,400 and $800 \mu \mathrm{g} / \mathrm{mL}$, respectively.

These events are compatible with some types of programmed cells death. As expectable, among fractions and in accordance with the obtained values of viability assays (Figure 3), the most notorious effects were observed on the coloured fraction, where it is possible to see necrosis event in the highest concentration $(800 \mu \mathrm{g} / \mathrm{mL})$, which is characterized by mitochondrial and cellular swelling following plasma membrane disruption. On the other hand, at $200 \mu \mathrm{g} / \mathrm{mL}$, we only observed morphological changes, including condensed chromatin and fragmented nuclei, which are characteristics of apoptosis.

Similar results were already reported concerning other phenolic-rich fractions [5,26,43,49,50]. Particularly, Gonçalves and collaborators [5] revealed that $800 \mu \mathrm{g} / \mathrm{mL}$ of anthocyanins-rich fraction from sweet cherries causes necrosis on Caco-2 cells, after 24 hours of exposure. Focusing on individual phenolics, Shang and colleagues [51] reported that quercetin at $160 \mu \mathrm{M}$ causes apoptosis on AGS cells. Furthermore, $100 \mu \mathrm{M}$ cyanidin 3-O-rutinoside and $50 \mu \mathrm{M}$ of catechin derivatives showed potential to induce apoptosis on human adenocarcinoma HepG2 cells and breast cancer MDA-MB-231 cells, after 24 and 48 hours of exposure, respectively [51,52].

\subsection{Cytoprotective effects}

The final step of this work was to evaluate the capacity of phenolic-targeted fractions obtained from sweet cherries to protect AGS and SH-SY5Y cells against induced 
oxidative stress. As it is known, oxidative stress plays a crucial role in cancer development and progression, and hence, its relief will interfere with the cancer tumor growth and metastasis. Therefore, it is not surprising that phenolics have been intensively studied in order to discover their full biological potential. Once again, the cellular viability of AGS and SH-SY5Y cells was determined by MTT and LDH leakage assays. The total protection was compared to stressed control cells. In a general way, the obtained outcome is very promising and revealed phenolics can protect against oxidative stress and apoptosis.

Firstly, it was assessed the capacity of phenolics to protect AGS cells after exposure to $t$ - $\mathrm{BHP}$ and $\mathrm{H}_{2} \mathrm{O}_{2}$. In most assays, the total protection was accomplished in the lowest tested concentrations ( 50 and $100 \mu \mathrm{g} / \mathrm{mL}$ ). Regarding the protection offered by phenolics against $t$-BHP (Figure 6A), we observe that the non-coloured fraction was the most effective, showing increments in cell viability of $3.42 \%$ at $50 \mu \mathrm{g} / \mathrm{mL}$. On the other hand, slight decreases were observed as the coloured fraction concentration increased, as well as at 200 and $800 \mu \mathrm{g} / \mathrm{mL}$ of the total extract. Furthermore, a dose-dependent protection was observed in AGS cells against oxidative damage induced by $600 \mu \mathrm{M} \mathrm{H}_{2} \mathrm{O}_{2}$ (Figure $6 \mathrm{~B})$. Amongst fractions, the coloured fraction showed the highest protection, revealing increments of viability between $27.10 \%$ and $67.17 \%$, followed by the total extract and non-coloured fraction. Regarding the insult with different concentrations of $\mathrm{H}_{2} \mathrm{O}_{2}$ for 24 hours (Figure 6C), the total extract and non-coloured fractions showed the most promising data. However, in the highest induced toxicity, the coloured fraction was the better one, which can be considered another support concerning the strong antioxidant effects showed by anthocyanins.
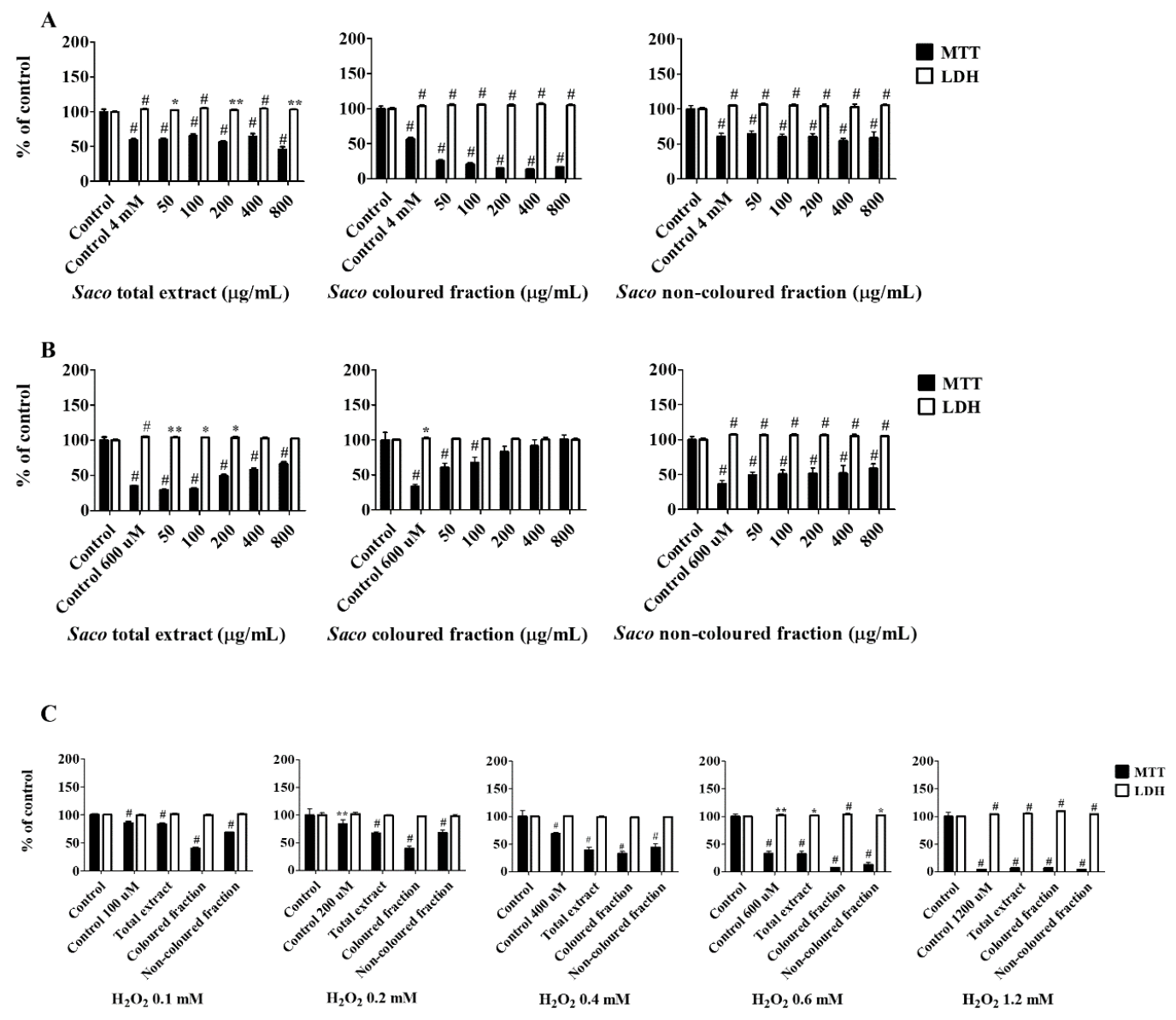

Figure 6. Effects of sweet cherry phenolic-targeted fractions on cellular viability of AGS cells, assessed by 3-(4,5-dimethylthiazol-2-yl)-2,5-diphenyltetrazolium bromide (MTT) reduction and lactate dehydrogenase leakage (LDH) assays, after exposure to Saco frac- 
tions for 24 hours, and then insulted with (A) tert-butyl hydroperoxide (4 mM; 2 hours), and (B) hydrogen peroxide $\left(\mathrm{H}_{2} \mathrm{O}_{2} ; 600 \mu \mathrm{M} ; 2\right.$ hours). Additionally, and after treatment using the non-toxic concentration of $50 \mu \mathrm{g} / \mathrm{mL}$ of each fraction, cells were also exposed to different concentrations of $\mathrm{H}_{2} \mathrm{O}_{2}(100,200,400,600$ and $1200 \mu \mathrm{M})$ for 24 hours (C). Values show mean \pm SEM of six independent assays performed in triplicate compared to the respective control $\left({ }^{*} \mathrm{p}<0.05,{ }^{* *} \mathrm{p}<0.01\right.$ and $\left.\# \mathrm{p}<0.0001\right)$.

In SH-S5Y5, all targeted fractions showed effectiveness in protecting these cells against the neurotoxicity induced by glutamate, in a dose-dependent manner. The total protection was again achieved in the lowest tested concentrations (50 and $100 \mu \mathrm{g} / \mathrm{mL}$ ). Without surprises, the total extract was the most promising one, promoting rises in cell viability ranging from 0.34 and $18.44 \%$, which suggests that the combination of different phenolics is an added value in intensifying the health benefits (Figure 7A).

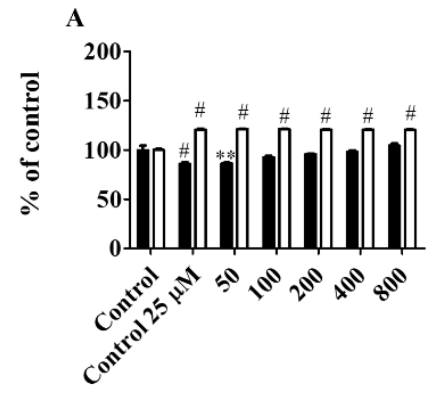

Saco total extract $(\mu \mathrm{g} / \mathrm{mL})$

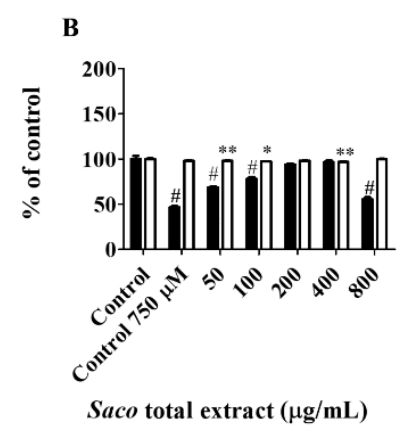

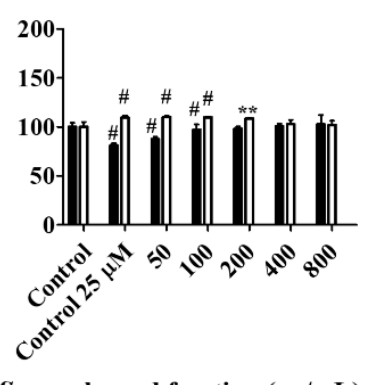

Saco coloured fraction $(\mu \mathrm{g} / \mathrm{mL})$
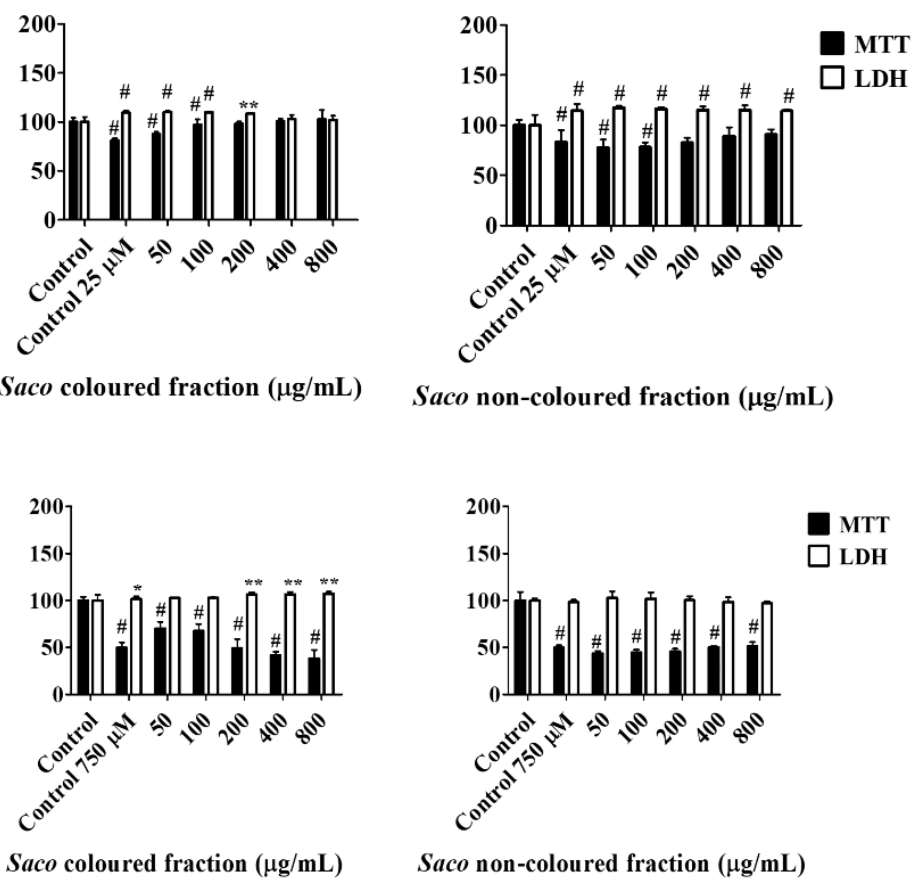

Saco non-coloured fraction $(\mu \mathrm{g} / \mathrm{mL})$

D

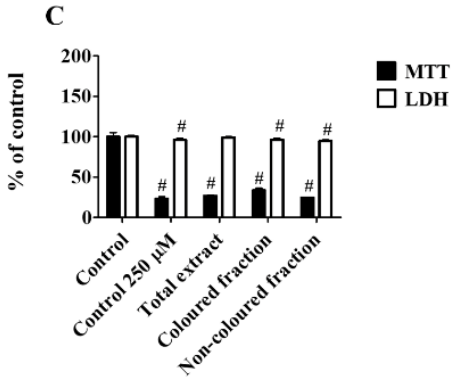

t-BHP $250 \mu \mathrm{M}$

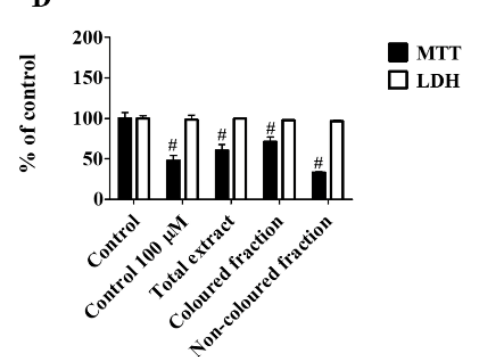

$t$-BHP $100 \mu \mathrm{M}$

Figure 7. Effects of sweet cherry phenolic-targeted fractions on cellular viability of SH-SY5Y cells, assessed by 3-(4,5-dimethylthiazol-2-yl)-2,5-diphenyltetrazolium bromide (MTT) reduction and lactate dehydrogenase leakage (LDH) assays, after exposure to Saco fractions for 24 hours and then insulted with (A) glutamate $(25 \mu \mathrm{M} ; 6$ hours), and (B) hydrogen peroxide $(750 \mu \mathrm{M} ; 24$ hours). Additionally, and after treatment using the non-toxic concentration of $50 \mu \mathrm{g} / \mathrm{mL}$ of each fraction for 6 and 24 hours, cells were insulted with tert-butyl hydroperoxide ( $t$-BHP) for further 12 and 24 hours, at concentrations of 250 (C) or $100 \mu \mathrm{M}(\mathrm{D})$, respectively. Values show mean \pm SEM of six independent 
assays performed in triplicate compared to the respective control ${ }^{*} \mathrm{p}<0.05,{ }^{* *} \mathrm{p}<0.01$ and \# $\mathrm{p}<0.0001)$.

Regarding the protective effects offered by phenolics against induced oxidative stress promoted by $\mathrm{H}_{2} \mathrm{O}_{2}$, the coloured fraction revealed pro-oxidant behavior in the highest tested concentrations $(100-800 \mu \mathrm{g} / \mathrm{mL})$. On contrary, the non-coloured extract in all concentrations and the total extract $(\leq 400 \mu \mathrm{g} / \mathrm{mL})$ showed capacity to protect these cells in a dose-dependent manner (Figure 7B). Furthermore, phenolic-target fractions also presented potential to protect neuronal cells after exposure to $t$-BHP at different concentrations and times (Figure 7C-D). In both experiments, the coloured fraction was the most notorious for attenuating the $t$-BHP-induced cytotoxicity, followed by the total extract and non-coloured. The obtained results revealed that the capacity of phenolics to protect against oxidative injury increases with the time of exposition, and also with the concentration of the pro-oxidant agent.

Overall, the protection showed by phenolics is, in part, mediated by antioxidant mechanisms. Furthermore, the interactions occurring between different phenolic subclasses, also serve to increase their biological potential. Indeed, it was already documented that phenolics can pass through the cellular membrane, and hence, scavenging radicals before them can cause damage in cells and promote apoptosis $[5,12,43]$. Regarding individual compounds, Vepsäläinen and collaborators [53] already reported that quercetin and anthocyanin-rich extracts from berries $(0.25$ to $31 \mu \mathrm{g} / \mathrm{mL})$ can significantly decrease reactive oxygen species production on neuroblastoma cells (46\% and 86\%), in a dose-dependent manner. Other phenolics, including phenolic acids, also showed ability to attenuate oxidative stress in cancer cells [5,54-56]. Even so, it is also important to note that these effects are strongly dependent on the time and concentration of the insulting agent.

\section{Materials and Methods}

\subsection{Reagents}

All chemicals used were of analytical grade. N-(1-naphthyl)ethylenediamine dihydrochloride, sulfanilamide and sodium nitroprusside dihydrate (SNP) were purchased from Alfa Aesar (Karlsruhe, Germany). Dulbecco's Modified Eagle Medium with GlutaMAX ${ }^{\mathrm{TM}}$ supplement (DMEM + GlutaMAX), iNOS primary antibody and anti-rabbit HRP-conjugated secondary antibody were obtained from Invitrogen (Grand Island, NY, USA). COX-2 primary antibody and anti-mouse HRP-conjugated secondary antibody were obtained from Santa Cruz Biotechnology (Texas, USA). Fetal bovine serum, antibiotics $(10,000 \mathrm{U} / \mathrm{mL}$ penicillin, $10,000 \mathrm{mg} / \mathrm{mL}$ streptomycin $)$, trypsin-ethylenediaminetetraacetic acid solution, 3-(4,5-dimethylthiazol-2-yl)-2,5-diphenyltetrazolium bromide (MTT), dimethyl sulfoxide (DMSO), dexamethasone and $\beta$-nicotinamide adenine dinucleotide (NADH) were from Sigma-Aldrich (St. Louis, MO, USA). Water was deionized using a Milli-Q water purification system (Millipore Ibérica, Madrid, Spain).

\subsection{Samples}

Approximately $1 \mathrm{~kg}$ of Saco sweet cherry fruits, grown in Fundão region (Portugal), were harvested by hand in June 2017, at the commercial maturity stage. Within 1 hour of harvest, samples were transported to the laboratory facilities at $0{ }^{\circ} \mathrm{C}$. Then, their pits were removed and separated from the pulp, which in turn, was frozen with liquid nitrogen and maintained at $-80{ }^{\circ} \mathrm{C}$ until lyophilization. After lyophilization, the pulp was powdered and divided into three aliquots used for the preparation of the extracts.

\subsection{Extracts' preparation}

The preparation of the cherry extracts was performed according to a previous method [5]. Briefly, $1 \mathrm{~g}$ of powered cherries was extracted with $20 \mathrm{~mL}$ ethanol $70 \%$ during 2 hours, under agitation at room temperature, and protected from light. Then, the 
obtained homogenates were centrifuged at $2900 \mathrm{~g}$ for $10 \mathrm{~min}$. After that time, the supernatant, i.e., the solvent cherry extract, was collected and evaporated under reduced pressure at $30{ }^{\circ} \mathrm{C}$. In order to obtain the fractions enriched in phenolic compounds, a solid-phase extraction (SPE) procedure was performed using Sep-Pak C18 solid-phase extraction columns (70 mL/10,000 mg; Macherey-Nagel, Düren, Germany). The resulting extract was dissolved in $50 \mathrm{~mL}$ deionized water and placed in the SPE cartridge preconditioned with $20 \mathrm{~mL}$ ethyl acetate, $20 \mathrm{~mL}$ ethanol, and $20 \mathrm{~mL} 0.01 \mathrm{~mol} / \mathrm{L} \mathrm{HCl}$. The loaded cartridge was again washed with $3 \mathrm{~mL} 0.01 \mathrm{~mol} / \mathrm{L} \mathrm{HCl}$. The fraction enriched in non-coloured phenolics (fraction I) was eluted with $20 \mathrm{~mL}$ ethyl acetate, while the fraction with anthocyanins (fraction II) was eluted with $40 \mathrm{~mL}$ ethanol containing $0.1 \% \mathrm{HCl}$. To obtain the combined extract (fraction III), another SPE column was performed, being preconditioned as previously described, then the extract was passed through the column and eluted with $40 \mathrm{~mL}$ ethanol containing $0.1 \% \mathrm{HCl}$. Next, each eluate was concentrated under reduced pressure, and the obtained residues were dissolved in deionized water and lyophilized. Finally, they were stored in silica at room temperature, and protected from light, until their use.

The phenolic profile of each fraction was already analysed by chromatographic techniques. Among phenolics, hydroxycinnamic acids were the main phenolic compounds found in non-coloured fraction (99.7\%) and total extract $(69.8 \%)$, while cyanidin $3-O$-rutinoside was the predominant anthocyanin in coloured fraction $(81.5 \%)$ and total extract $(24.5 \%)$ [5].

\subsection{Cell models}

AGS cells were acquired from Sigma-Aldrich (St. Louis, MO, USA), and NHDF cells from the American Type Culture Collection (LGC Standards S.L.U., Barcelona, Spain). SH-SY5Y and RAW cells were kindly provided by colleagues from the CICS-UBI (Covilhã, Portugal). AGS and SH-SY5Y cells were cultured in DMEM+ GlutaMAX, while RAW and NHDF cells were maintained with DMEM and RPMI 1640 medium supplemented with $2 \mathrm{mM}$ L-glutamine, $10 \mathrm{mM}$ 4-(2-hydroxyethyl)-1-piperazineethanesulfonic acid and $1 \mathrm{mM}$ sodium pyruvate, respectively. All mediums were supplemented with $10 \%$ fetal bovine serum and $1 \%$ penicillin/streptomycin, and maintained in a humidified atmosphere of $5 \% \mathrm{CO}_{2}$, at $37^{\circ} \mathrm{C}$.

After a few passages, and in order to evaluate the cytotoxic and pro-apoptotic effects of the cherry fractions on RAW 246.7 macrophages, AGS, SH-SY5Y and NHDF cells, they were seeded in 96 well-plates at a density of $2.5 \times 10^{4}, 1.0 \times 10^{4}, 3.0 \times 10^{4}$ and $1.0 \times 10^{4}$ cells per $\mathrm{mL}$, respectively. After 24 hours, the medium was removed, and different concentrations of cherry fractions (ranging from 50-800 $\mu \mathrm{g} / \mathrm{mL}$ ) dissolved in the medium containing $0.5 \%(v / v)$ DMSO were added, and plates were incubated again for another 24 hours $[26,50]$.

To evaluate the cytoprotective effects of cherry fractions on cells, preliminary assays were done to determine the appropriate concentration and exposure time of each oxidative stress inducer able to cause around 50\% cell death (data not shown). Therefore, in AGS cells, 24 hours later to the exposure with the fractions, the medium was removed, and cells were exposed to $t$-BHP ( $4 \mathrm{mM}$; 2 hours) or $\mathrm{H}_{2} \mathrm{O}_{2}(600 \mu \mathrm{M} ; 2$ hours). Additionally, and after treatment using the non-toxic concentration of $50 \mu \mathrm{g} / \mathrm{mL}$ of each fraction, cells were also exposed to different concentrations of $\mathrm{H}_{2} \mathrm{O}_{2}(100,200,400,600$ and 1200 $\mu \mathrm{M})$ for 24 hours. On the other hand, SH-SY5Y cells were exposed to glutamate (25 $\mu \mathrm{M} ; 6$ hours), $\mathrm{H}_{2} \mathrm{O}_{2}$ (750 $\mu \mathrm{M} ; 24$ hours) or $t$-BHP (100 $\mu \mathrm{M} ; 24$ hours) after 24 hours of treatment with each fraction [26]. To deeper the outcome, SH-SY5Y cells were also exposed to 250 $\mu \mathrm{M} t$-BHP for 12 hours, after 6 hours of treatment with each fraction.

All experiments were conducted in the cells' logarithmic growth phase. Results are expressed as percentage of the respective control and correspond to the mean \pm standard error of the mean (SEM) of, at least, six independent experiments performed in triplicate. 
The release of the stable cytosolic enzyme lactate dehydrogenase (LDH) into the medium is used as a marker for loss of membrane integrity, and it can be assessed spectrophotometrically at $340 \mathrm{~nm}$ (Bio-Rad Laboratories, Hercules, USA), in a kinetic mode. It is based on the conversion of pyruvate to lactate by LDH, using NADH as a cofactor [5]. Briefly, after each assay, $50 \mu \mathrm{L}$ of culture medium was placed in 96-well plates and mixed with NADH (252.84 mM) and pyruvate (14.99 mM). Both pyruvate and NADH solutions were prepared in phosphate-buffered saline (PBS; $\mathrm{pH} 7.4$ ). A decrease in absorbance is directly related to the decrease of NADH levels. Untreated cells were used as a control.

\subsubsection{MTT reduction assay}

Cell viability was determined using the colorimetric 3-(4,5-dimethylthiazol-2-yl)-2,5-diphenyltetrazolium bromide (MTT) assay. To that, at the end of each experiment, the medium was removed and MTT $(0.5 \mathrm{mg} / \mathrm{mL}$ dissolved in the appropriate serum-free medium) was added and incubated at $37^{\circ} \mathrm{C}$ for 4 hours. Afterwards, MTT was discarded, and the formazan crystals were solubilized using DMSO. The absorbance was read at $570 \mathrm{~nm}$ using a microplate reader Bio-Rad Xmark spectrophotometer. Untreated cells were used as a control.

\subsection{Intracellular polyphenols' staining and fluorescence microscopy}

The morphological studies were based on previous work [50]. Briefly, AGS cells were seeded at density of $7.5 \times 10^{4}$ cells per $\mathrm{mL}$, in coverslips placed in 24-multiwell plates. After 24 hours, the medium was discarded, and the adherent cells were treated with different concentrations of each fraction $(50-800 \mu \mathrm{g} / \mathrm{mL})$ for another equal period of time. Next, the medium was removed, and cells were carefully washed with PBS and then fixed in coverslips with $4 \%$ of paraformaldehyde solution prepared in PBS, followed by 10 min of incubation, at room temperature. Then, the solution was rejected, and the fixed cells were again repeatedly rinsed with PBS. Nuclear morphology was observed using 4,6-diamidino-2-phenylindole (DAPI), added to the fixed cells at $1 \mu \mathrm{g} / \mathrm{mL}$ for $10 \mathrm{~min}$ at room temperature. Finally, cells were washed twice with PBS and chromatin fluorescence was analyzed using a Zeiss AxioImager A1 fluorescence microscope. Digital images were generated with AxioVision 4.8.2 software.

\subsection{Determination of $\bullet N O$ levels in culture medium interference}

The nitrite accumulation in the culture medium was determined according to a method described by Taciak and colleagues [57]. Cells were cultured at density of $15 \times 10^{4}$ cells per $\mathrm{mL}$ in 96 well-plates for 24 hours at $37^{\circ} \mathrm{C}$ and $5 \% \mathrm{CO}_{2}$. Then, the medium was removed, and cells were exposed to increasing concentrations of each fraction for 2 hours. After that period, cells were stimulated with $1 \mu \mathrm{g} / \mathrm{mL}$ LPS for further 22 hours. The nitrite conversion was determined using a mixture composed of $75 \mu \mathrm{L}$ of culture media mixed with an equal volume of Griess reagent $(1 \%$ sulphanilamide and $0.1 \%$ $\mathrm{N}$-[naphth-1-yl]ethylenediamine dihydrochloride in $2 \% \mathrm{H}_{3} \mathrm{PO}_{4}$ ), after an incubation period of $10 \mathrm{~min}$, in the dark, at room temperature. The absorbance was then measured at $560 \mathrm{~nm}$ in a microplate reader (Bio-Rad Laboratories, Hercules, USA). $\bullet$ NO levels were expressed as percentage of the $\cdot \mathrm{NO}$ in cells exposed to LPS (positive control) and correspond to the mean \pm SEM of six independent experiments, performed in triplicate. Dexamethasone at equal concentrations of each tested concentration was used as positive control.

3.7. Detection of inducible nitric oxide synthase (iNOS) and cyclooxygenase (COX)-2 expression

Western blot analysis was carried out with protein extracts obtained from RAW 264.7 cells based on the method reported by Pereira and colleagues [58], with some modifications. Briefly, RAW 264.7 cells were cultured in 6 well-plates at density of 50x104 for 24 hours. Then, the medium was removed, and the cells were exposed to each fraction for 2 hours, followed by the addition of $1 \mu \mathrm{g} / \mathrm{mL}$ LPS for further 24 hours. Afterwards, cells were washed with PBS, scraped, and incubated on ice with ice-cold RIPA lysis 
buffer $(150 \mathrm{mM} \mathrm{NaCl}, 0.5 \%$ Sodium deoxycholate, $0.1 \%$ SDS, 1\% Triton X-100, $50 \mathrm{mM}$ Tris $\mathrm{pH}$ 8.0, $1 \mathrm{mM}$ PMSF, $1 \mathrm{mM}$ Sodium orthovanadate and $40 \mu \mathrm{L} / \mathrm{mL}$ of Complete EDTA Free protease inhibitor cocktail) for $30 \mathrm{~min}$. Then, cell debris were removed by microcentrifugation $(10,000 \mathrm{~g}$ for $10 \mathrm{~min})$. Total protein content was measured using Pierce BCA Protein Assay Kit (Thermo Fisher Scientific, Waltham, USA) according to the manufacturer's recommendations. After quantification, $30 \mu \mathrm{g}$ of total protein was mixed with loading buffer containing $4 \% \beta$-mercaptoethanol, followed by denaturation for 5 min at $100{ }^{\circ} \mathrm{C}$, and then loaded in $8 \%$ or $12.5 \%$ SDS-PAGE. Proteins were subsequently electrically transferred onto polyvinylidene difluoride membranes (Millipore, Merck, Milford, USA), using a Trans-Blot ${ }^{\circledR}$ Cell system (Bio-Rad, Hercules, USA). Next, membranes were blocked with a solution of 5\% skimmed milk powder in Tris-buffered saline (TBS), during 1 hour at room temperature, and incubated overnight at $4{ }^{\circ} \mathrm{C}$ with primary antibodies rabbit anti-iNOS (1:300) and mouse anti-COX-2 (1:100). After, membranes were washed at room temperature with TBS containing $0.1 \%$ of Tween and incubated for 1 hour at room temperature with the respective HRP-conjugated secondary antibodies (anti-rabbit 1:20 000 and anti-mouse 1:40 000). Then, membranes were washed, and antibody binding was detected using the SuperSignal ${ }^{\mathrm{TM}}$ West Pico PLUS Chemiluminescent Substrate (ThermoFisher Scientific, Grand Island, USA) according to the manufacturer's instructions. Images of blots were captured with the ChemiDoc MP Imaging system (Bio-Rad, Hercules, USA). Additionally, the expression of iNOS and COX-2 was normalized with $\beta$-actin (loading control). Then, blots were incubated for 2 hours at room temperature with mouse anti- $\beta$-actin (1:20 000) before incubation for 1 hour with HRP-conjugated goat anti-mouse secondary antibody (1:40 000). Next, images were acquired, and protein bands were quantified using the Image Lab software (Bio-Rad, Hercules, USA). The results correspond to the mean \pm SEM of, at least, four independent experiments.

\section{8. iNOS and COX-2 gene expression analyses}

The quantitative analysis regarding iNOS and COX-2 gene expression by qPCR was conducted under similar conditions to those applied to perform Western blot assay. The cells were harvested and total cellular RNA was extracted using NZY total RNA Isolation kit (NZYTech, Portugal) according to the manufacture's instructions. For each RT-PCR reaction, total RNA was loaded in One-step NZYSpeedy RT-qPCR Probe kit (NZYTech, Portugal) to carry out the synthesis of cDNA and the PCR reaction in a CFX Connect Real-Time PCR Detection System (BIO-RAD, USA). $\beta$-actin was employed as an internal control. The oligonucleotide primers used were: 5'-GAGCGAGTTGTGGATTGTC-3' (forward) and 5'-CTCCTTTGAGCCCTTTGT-3' (reward) for iNOS; 5'-GGAGAGACTATCAAGATAGT-3' 5'-ATGGTCAGTAGACTTTTACA-3' and 5'-CTGTCCCTGTATGCCTCTG (forward) and 5'-ATGTCACGCACGATTTCC-3' ward) for $\beta$-actin. The thermal cycling conditions were as follows: $20 \mathrm{~min}$ at $50{ }^{\circ} \mathrm{C}$ for cDNA synthesis, $2 \mathrm{~min}$ at $95^{\circ} \mathrm{C}$ for retrotranscriptase inactivation, followed by 40 cycles of denaturation at $95{ }^{\circ} \mathrm{C}$ for $5 \mathrm{~s}$ and annealing/extension at $55^{\circ} \mathrm{C}$ for $1 \mathrm{~min}$. The fluorescence signal was detected at the end of each cycle. The results were analysed with BIORAD CFX Manager 3.1 (BIO-RAD), and a melting curve was used to confirm the specificity of the products. The expression levels of the target genes were normalized to the reference gene $\beta$-actin. At least, three independent experiments were performed and all reactions were done in duplicate to confirm reproducibility.

\subsection{Determination of $\bullet N O$ levels in cell-free system}

The capacity of sweet cherry extracts in capturing $\bullet \mathrm{NO}$ was based on the work of Gonçalves et al. [5]. Briefly, five different concentrations equal to the ones tested in cells were dissolved in potassium phosphate buffer (100 mM, pH 7.4), and mixed with $100 \mu \mathrm{L}$ SNP (20 mM). Blank and control contained $100 \mu \mathrm{L}$ phosphate buffer and $100 \mu \mathrm{L}$ SNP. Then, the plates were incubated at room temperature for 1 hour, under light. Subsequently, an equal volume of Griess reagent (1\% sulfanilamide and $0.1 \%$ naphthyleth- 
ylenediamine in $2 \% \mathrm{H}_{3} \mathrm{PO}_{4}$ ) was added to each well, and plates were incubated for $10 \mathrm{~min}$ in a dark (blanks received $100 \mu \mathrm{L}$ of $\mathrm{H}_{3} \mathrm{PO}_{4}$ ). After that time, the absorbance was recorded at $560 \mathrm{~nm}$. The $\cdot \mathrm{NO}$ scavenging activity was determined through the comparison of the absorbances between the extracts and the control and correspond to the mean \pm SEM of three independent experiments, performed in triplicate.

\title{
3.10. Statistical analysis of results
}

Statistical analysis was performed using Graphpad Prism Version 6.01 (San Diego, CA, USA). One-way ANOVA followed by Dunnett's post-hoc test (LDH and MTT assays) were used to determine the statistical significance in comparison to control. Values of $P<0.05$ were considered statistically significant.

\section{Conclusions}

Considering the current interest in cherry fruits given their high content in phenolic compounds as functional foods, the obtained data revealed that phenolic-target fractions from sweet cherries can exert anti-inflammatory and antiproliferative properties on RAW macrophages and AGS cells, respectively, and also capacity to counteract oxidative stress in cancer cells. Altogether, this work sustains their incorporation on pharmaceutical products, nutraceuticals, and dietary supplements, once phenolics can be considered promising agents in the prevention and/or treatment of diseases mediated by inflammatory mediators, reactive species and free radicals. Notwithstanding, in order to exclude the risk of toxicity and demonstrate their safety, clinical trials should be conducted to explore the full biological potential of sweet cherries and their safe dosage.

\begin{abstract}
Author Contributions: Conceptualization, A.C.G. and L.R.S.; methodology, A.C.G., A.R.C. and J.D.F.-F.; software, A.C.G., A.R.C. and J.D.F.-F.; validation, A.C.G., J.D.F.-F. and A.R.C., A.F., G.A. and L.R.S.; formal analysis, A.C.G., A.R.C. and J.D.F.-F.; investigation, A.C.G. and J.D.F.-F.; resources, A.R.C., J.D.F.-F., G.A. and L.R.S.; data curation, A.C.G., A.R.C. and J.D.F.-F.; writing-original draft preparation, A.C.G.; writing - review and editing, A.C.G., A.R.C., J.D.F-F, A.F., G.A. and L.R.S.; visualization, all authors; supervision, A.F., G.A. and L.R.S.; project administration, G.A.; funding acquisition, J.D.F.-F., G.A and L.R.S. All authors have read and agreed to the published version of the manuscript.
\end{abstract}

Funding: This work was partially supported by CICS-UBI (UIDP/00709/2020) financed by National Funds from Fundação para a Ciência e a Tecnologia (FCT), Community Funds (UIDB/00709/2020) and CENTRO-04-3559-FSE-000162. The authors are grateful to Foundation for Science and Technology (FCT), Ministry of Science, Technology and Higher Education (MCTES), European Social Fund (EFS) and Europe Union (EU) for the PhD fellowships of Ana C. Gonçalves (2020.04947.BD) and Ana R. Costa (UI/BD/151025/2021). José D. Flores-Félix was supported by European Union's Horizon 2020 research and innovation programme under the Marie Skłodowska-Curie grant agreement No 101003373.

Informed Consent Statement: Not applicable.

Data Availability Statement: Data are contained within this article.

Conflicts of Interest: The authors declare no conflict of interest.

\section{References}

1. Atanasov, A.G.; Zotchev, S.B.; Dirsch, V.M.; Orhan, I.E.; Banach, M.; Rollinger, J.M.; Barreca, D.; Weckwerth, W.; Bauer, R.; Bayer, E.A.; Majeed, M.; Bishayee, A.; Bochkov, V.; Bonn, G.K.; Braidy, N.; Bucar, F.; Cifuentes, A.; D’Onofrio, G.; Bodkin, M.; Diederich, M.; Dinkova-Kostova, A.T.; Efferth, T.; El Bairi, K.; Arkells, N.; Fan, T.P.; Fiebich, B.L.; Freissmuth, M.; Georgiev, M.I.; Gibbons, S.; Godfrey, K.M.; Gruber, C.W.; Heer, J.; Huber, L.A.; Ibanez, E.; Kijjoa, A.; Kiss, A.K.; Lu, A.; Macias, F.A.; Miller, M.J.S.; Mocan, A.; Müller, R.; Nicoletti, F.; Perry, G.; Pittalà, V.; Rastrelli, L.; Ristow, M.; Russo, Gian L.; 
Silva, A.S.; Schuster, D.; Sheridan, H.; Skalicka-Woźniak, K.; Skaltsounis, L.; Sobarzo-Sánchez, E.; Bredt, D.S.; Stuppner, H.; Sureda, A.; Tzvetkov, N.T.; Vacca, R.A.; Aggarwal, B.B.; Battino, M.; Giampieri, F.; Wink, M.; Wolfender, J.L.; Xiao, J.; Yeung, AW.K.; Lizard, G.; Popp, M.A.; ; Heinrich, M.; Berindan-Neagoe, I.; Stadler, M.; Daglia, M.; Verpoorte, R.; Supuran, C.T. Natural products in drug discovery: advances and opportunities. Nat. Rev. Drug Discov. 2021, 20, 200-216, doi:10.1038/s41573-020-00114-z.

2. Newman, D.J.; Cragg, G.M. Natural products as sources of new drugs over the nearly four decades from 01/1981 to 09/2019. J. Nat. Prod. 2020, 83, 770-803, doi:10.1021/acs.jnatprod.9b01285.

3. Natić, M.; Zagorac, D.D.; Ćirić, I.; Meland, M.; Rabrenović, B.; Akšić, M.F. Cold pressed oils from genus Prunus. In Cold Pressed Oils; Ramadan, M.F., Ed.; Academic Press: San Diego, 2020; pp. 637-658 ISBN 9780128181881.

4. Gonçalves, A.C.; Flores-Félix, D.; Costa, A.R.; Falcão, A.; Alves, G.; Silva, L.R. Hepatoprotective effects of sweet cherry extracts (cv. Saco). Foods 2021, 10, 2623.

5. Gonçalves, A.C.; Rodrigues, M.; Santos, A.O.; Alves, G.; Silva, L.R. Antioxidant status, antidiabetic properties and effects on Caco-2 cells of colored and non-colored enriched extracts of sweet cherry fruits. Nutrients 2018, 10, 1688, doi:10.3390/nu10111688.

6. Matias, A.A.; Rosado-Ramos, R.; Nunes, S.L.; Figueira, I.; Serra, A.T.; Bronze, M.R.; Santos, C.N.; Duarte, C.M.M. Protective effect of a (poly)phenol-rich extract derived from sweet cherries culls against oxidative cell damage. Molecules 2016, 21, 1-16, doi:10.3390/molecules21040406.

7. Serra, A.T.; Duarte, R.O.; Bronze, M.R.; Duarte, C.M.M. Identification of bioactive response in traditional cherries from Portugal. Food Chem. 2011, 125, 318-325, doi:10.1016/j.foodchem.2010.07.088.

8. Gonçalves, A.C.; Bento, C.; Silva, B.M.; Silva, L.R. Sweet cherries from Fundão possess antidiabetic potential and protect human erythrocytes against oxidative damage. Food Res. Int. 2017, 95, 91-100, doi:10.1016/j.foodres.2017.02.023.

9. Jesus, F.; Gonçalves, A.C.; Alves, G.; Silva, L.R. Exploring the phenolic profile, antioxidant, antidiabetic and anti-hemolytic potential of Prunus avium vegetal parts. Food Res. Int. 2018, doi:10.1016/j.foodres.2018.08.079.

10. Zhang, X.; Jiang, Z.; Yusupov, Z.; Zhang, M.; Zhang, D.; Tojibaev, K.; Meng, Y.; Deng, T. Prunus sunhangii: A new species of Prunus from central China. Plant Divers. 2019, 41, 19-25, doi:10.1016/j.pld.2019.01.003.

11. Nunes, A.R.; Gonçalves, A.C.; Alves, G.; Falcão, A.; García-Viguera, C.; Moreno, D.A.; Silva, L.R. Valorisation of Prunus avium L. by-products: Phenolic composition and effect on Caco-2 cells viability. Foods 2021, 10, In press.

12. Bernardo, J.; Ferreres, F.; Gil-Izquierdo; Valentão, P.; Andrade, P.B. Medicinal species as MTDLs: Turnera diffusa Willd. Ex Schult inhibits CNS enzymes and delays glutamate excitotoxicity in SH-SY5Y cells via oxidative damage. Food Chem. Toxicol. 2017, 106, 466-476, doi:10.1016/j.fct.2017.06.014.

13. Bento, C.; Gonçalves, A.C.; Silva, B.; Silva, L.R. Assessing the phenolic profile, antioxidant, antidiabetic and protective effects against oxidative damage in human erythrocytes of peaches from Fundão. J. Funct. Foods 2018, 43, 224-233, doi:10.1016/j.jff.2018.02.018.

14. Moita, E.; Gil-Izquierdo, A.; Sousa, C.; Ferreres, F.; Silva, L.R.; Valentão, P.; Domínguez-Perles, R.; Baenas, N.; Andrade, P.B. Integrated analysis of COX-2 and iNOS derived inflammatory mediators in LPS-stimulated RAW macrophages pre-exposed to Echium plantagineum L. bee pollen extract. PLoS One 2013, 8, 1-11, doi:10.1371/journal.pone.0059131.

15. Sousa, C.; Moita, E.; Valentão, P.; Fernandes, F.; Monteiro, P.; Andrade, P.B. Effects of colored and noncolored phenolics of Echium plantagineum L. bee pollen in Caco-2 cells under oxidative stress induced by tert-butyl hydroperoxide. J. Agric. Food Chem. 2015, 63, 2083-2091, doi:10.1021/jf505568h.

16. Shahidi, F.; Yeo, J. Bioactivities of phenolics by focusing on suppression of chronic diseases: a review. Int. J. Mol. Sci. 2018, 25, 1-16, doi:10.3390/ijms19061573.

17. Sharifi-Rad, M.; Anil Kumar, N. V.; Zucca, P.; Varoni, E.M.; Dini, L.; Panzarini, E.; Rajkovic, J.; Tsouh Fokou, P.V.; Azzini, E.; Peluso, I.; Prakash A.M.; Nigam, M.; Rayess; Y.; Beyrouthy, M.; Polito, L.; Iriti, M.; Martins, N.; Martorell, M.; Docea, 
A.O.; Setzer, W.N.; Calina, D.; Cho, W.C.; Sharifi-Rad, J. Lifestyle, oxidative stress, and antioxidants: Back and forth in the pathophysiology of chronic diseases. Front. Physiol. 2020, 11, 1-21, doi:10.3389/fphys.2020.00694.

18. Jesus, F.; Gonçalves, A.C.; Alves, G.; Silva, L.R. Health benefits of Prunus avium plant parts: An unexplored source rich in phenolic compounds. Food Rev. Int. 2020, doi:10.1080/87559129.2020.1854781.

19. Bento, C.; Gonçalves, A.C.; Silva, B.; Silva, L.R. Peach (Prunus persica): Phytochemicals and health benefits. Food Rev. Int. 2020, 1-32, doi:10.1080/87559129.2020.1837861.

20. Thibane, V.S.; Ndhlala, A.R.; Finnie, J.F.; Van Staden, J. Modulation of the enzyme activity of secretory phospholipase A 2 , lipoxygenase and cyclooxygenase involved in inflammation and disease by extracts from some medicinal plants used for skincare and beauty. South African J. Bot. 2019, 120, 198-203, doi:10.1016/j.sajb.2018.06.001.

21. Giménez-Bastida, J.A.; González-Sarrías, A.; Laparra-Llopis, J.M.; Schneider, C.; Espín, J.C. Targeting mammalian 5-lipoxygenase by dietary phenolics as an anti-inflammatory mechanism: A systematic review. Int. J. Mol. Sci. 2021, 22, doi:10.3390/ijms22157937.

Yahfoufi, N.; Alsadi, N.; Jambi, M.; Matar, C. The immunomodulatory and anti-inflammatory role of polyphenols. Nutrients 2018, 10, 1-23, doi:10.3390/nu10111618.

23. Kwon, D.; Ju, S.M.; Youn, G.S.; Choi, S.Y.; Park, J. Suppression of iNOS and COX-2 expression by flavokawain A via blockade of NF-kB and AP-1 activation in RAW 264.7 macrophages. Food Chem. Toxicol. 2013, 58, 479-486, doi:10.1016/j.fct.2013.05.031.

24. Moreira, R.; Fernandes, F.; Valentão, P.; Pereira, D.M.; Andrade, P.B. Echium plantagineum L. honey: Search of pyrrolizidine alkaloids and polyphenols, anti-inflammatory potential and cytotoxicity. Food Chem. 2020, 328, 127169, doi:10.1016/j.foodchem.2020.127169.

25. Andrade, C.; Ferreres, F.; Gomes, N.G.M.; Duangsrisai, S.; Srisombat, N.; Vajrodaya, S.; Pereira, D.M.; Gil-Izquierdo, A.; Andrade, P.B.; Valentão, P. Phenolic profiling and biological potential of ficus curtipes corner leaves and stem bark: 5-Lipoxygenase inhibition and interference with NO Levels in LPS-stimulated RAW264.7 Macrophages. Biomolecules 2019, 9, 1-17, doi:10.3390/biom9090400.

26. Pereira, R.B.; Pinto, D.C.G.A.; Pereira, D.M.; Gomes, N.G.M.; Silva, A.M.S.; Andrade, P.B.; Valentão, P. UHPLC-MS/MS profiling of Aplysia depilans and assessment of its potential therapeutic use: Interference on iNOS expression in LPS-stimulated RAW 264.7 macrophages and caspase-mediated pro-apoptotic effect on SH-SY5Y cells. J. Funct. Foods 2017, 37, 164-175, doi:10.1016/j.jff.2017.07.053.

27. Kim, E.O.; Min, K.J.; Kwon, T.K.; Um, B.H.; Moreau, R.A.; Choi, S.W. Anti-inflammatory activity of hydroxycinnamic acid derivatives isolated from corn bran in lipopolysaccharide-stimulated Raw 264.7 macrophages. Food Chem. Toxicol. 2012, 50, 1309-1316, doi:10.1016/j.fct.2012.02.011.

28. Jung, H.; Kwak, H.-K.; Hwang, K.T. Antioxidant and antiinflammatory activities of cyanidin-3-glucoside and cyanidin-3-rutinoside in hydrogen peroxide and lipopolysaccharide-treated RAW 264.7 cells. Food Sci. Biotechnol. 2014, 23, 2053-2062, doi:10.1007/s10068-014-0279-x.

29. Byung, H.K.; Sung, M.C.; Reddy, A.M.; Yeong, S.K.; Kyung, R.M.; Kim, Y. Down-regulatory effect of quercitrin gallate on nuclear factor- $\kappa \mathrm{B}$-dependent inducible nitric oxide synthase expression in lipopolysaccharide-stimulated macrophages RAW 264.7. Biochem. Pharmacol. 2005, 69, 1577-1583, doi:10.1016/j.bcp.2005.03.014.

30. Zhang, T.T.; Hu, T.; Jiang, J.G.; Zhao, J.W.; Zhu, W. Antioxidant and anti-inflammatory effects of polyphenols extracted from Ilex latifolia Thunb. RSC Adv. 2018, 8, 7134-7141, doi:10.1039/c7ra13569f.

31. Antwi, C.A.; Amisigo, C.M.; Adjimani, J.P.; Gwira, T.M. In vitro activity and mode of action of phenolic compounds on Leishmania donovani. PLoS Negl. Trop. Dis. 2019, 13, e0007206.

32. Britt, R.D.; Locy, M.L.; Tipple, T.E.; Nelin, L.D.; Rogers, L.K. Lipopolysaccharide-induced cyclooxygenase-2 expression in mouse transformed clara cells. Cell. Physiol. Biochem. 2012, 29, 213-222, doi:10.1159/000337602. 
33. Lin, W.N.; Lin, C.C.; Cheng, H.Y.; Yang, C.M. Regulation of cyclooxygenase-2 and cytosolic phospholipase A 2 gene expression by lipopolysaccharide through the RNA-binding protein HuR: Involvement of NADPH oxidase, reactive oxygen species and mitogen-activated protein kinases. Br. J. Pharmacol. 2011, 163, 1691-1706, doi:10.1111/j.1476-5381.2011.01312.x.

34. Jacob, R.A.; Spinozzi, G.M.; Vicky, A.; Kelley, D.S.; Prior, R.L.; Hess-Pierce; Kader, A.A. Consumption of cherries lowers plasma urate in healthy women. J. Nutr. 2003, 133, 1826-1829.

35. Delgado, J.; del Pilar Terrón, M.; Garrido, M.; Barriga, C.; Espino, J.; Paredes, S.D.; Rodríguez, A.B. Jerte Valley cherry-based product modulates serum inflammatory markers in rats and ringdoves. J. Appl. Biomed. 2012, 10, 41-50, doi:10.2478/v10136-011-0009-0.

36. Seeram, N.P.; Momin, R. a; Nair, M.G.; Bourquin, L.D. Cyclooxygenase inhibitory and antioxidant cyanidin glycosides in cherries and berries. Phytomedicine 2001, 8, 362-369, doi:10.1078/0944-7113-00053.

37. Xiong, H.; Cheng, Y.; Zhang, X.; Zhang, X. Effects of taraxasterol on iNOS and COX-2 expression in LPS-induced RAW 264.7 macrophages. J. Ethnopharmacol. 2014, 155, 753-757, doi:10.1016/j.jep.2014.06.023.

38. Karataş, A.; Orhan, C.; Tuzcu, M.; Şahin, N.; Özercan, İ.H.; Koca, S.S.; Juturu, V.; Şahin, K. Mango ginger (curcuma amada) inhibits collagen-induced arthritis by modulating inflammatory cytokine levels in rats. Turkish J. Med. Sci. 2020, 50, 2040-2047, doi:10.3906/sag-2004-105.

39. Limtrakul, P.; Yodkeeree, S.; Pitchakarn, P.; Punfa, W. Suppression of inflammatory responses by black rice extract in RAW 264.7 macrophage cells via downregulation of NF-kB and AP-1 signaling pathways. Asian Pacific J. Cancer Prev. 2015, 16, $4277-4283$.

40. Zielińska, D.Z.; Zieliński, H.Z.; Giménez-Bastida; Laparra-Llopis, J.M.; Giménez-Bastida, J.A. Caffeic acid modulates processes associated with intestinal inflammation. Nutrients 2021, 13, 554.

41. Gonçalves, A.C.; Nunes, A.R.; Falcão, A.; Alves, G.; Silva, L.R. Dietary effects of anthocyanins in human health: a comprehensive review. Pharmaceuticals 2021, 14, 690, doi:10.3390/ph14070690.

42. Guan, H.; Yang, H.; Yang, M.; Yanagisawa, D.; Bellier, J.-P.; Mori, M.; Takahata, S.; Nonaka, T.; Zhao, S.; Tooyama, I. Mitochondrial ferritin protects SH-SY5Y cells against $\mathrm{H}_{2} \mathrm{O}_{2}$-induced oxidative stress and modulates $\alpha$-synuclein expression. Exp. Neurol. 2017, 291, 51-61, doi:10.1016/j.expneurol.2017.02.001.

43. Ferreres, F.; Bernardo, J.; Andrade, P.B.; Sousa, C.; Gil-Izquierdo, A.; Valentão, P. Pennyroyal and gastrointestinal cells: multi-target protection of phenolic compounds against $t$-BHP-induced toxicity. RSC Adv. 2015, 5, 41576-41584, doi:10.1039/C5RA02710A.

44. Lage, N.N.; Anne, M.; Layosa, A.; Arbizu, S.; Chew, B.P.; Pedrosa, M.L.; Mertens-Talcott, S.; Talcott, S.; Noratto, G.D. Dark sweet cherry (Prunus avium) phenolics enriched in anthocyanins exhibit enhanced activity against the most aggressive breast cancer subtypes without toxicity to normal breast cells. J. Funct. Foods 2020, 64, 103710, doi:10.1016/j.jff.2019.103710.

45. Bastos, C.; Barros, L.; Duenas, M.; Calhelha, R.C.; Queiroz, M.J.R.P.; Santos-Buelga, C.; Ferreira, I.C.F.R. Chemical characterisation and bioactive properties of Prunus avium L.: The widely studied fruits and the unexplored stems. Food Chem. 2015, 173, 1045-1053, doi:10.1016/j.foodchem.2014.10.145.

46. Yen, G.C.; Chen, C.S.; Chang, W.T.; Wu, M.F.; Cheng, F.T.; Shiau, D.K.; Hsu, C.L. Antioxidant activity and anticancer effect of ethanolic and aqueous extracts of the roots of Ficus beecheyana and their phenolic components. J. Food Drug Anal. 2018, 26, 182-192, doi:10.1016/j.jfda.2017.02.002.

47. Condello, M.; Pellegrini, E.; Spugnini, E.P.; Baldi, A.; Amadio, B.; Vincenzi, B.; Occhionero, G.; Delfine, S.; Mastrodonato, F.; Meschini, S. Anticancer activity of "Trigno M", extract of Prunus spinosa drupes, against in vitro 3D and in vivo colon cancer models. Biomed. Pharmacother. 2019, 118, 109281, doi:10.1016/j.biopha.2019.109281.

48. Sajadimajd, S.; Bahramsoltani, R.; Iranpanah, A.; Patra, J.K.; Das, G.; Gouda, S.; Rahimi, R.; Rezaeiamiri, E.; Cao, H.; Giampieri, F.; Battino, M.; Tundis, R.; Campos, M.G.; Hosein, M. H.; Xiao, J. Advances on natural polyphenols as anticancer 
agents for skin cancer. Pharmacol. Res. 2020, 151, 104584, doi:10.1016/j.phrs.2019.104584.

49. Wang, E.; Liu, Y.; Xu, C.; Liu, J. Antiproliferative and proapoptotic activities of anthocyanin and anthocyanidin extracts from blueberry fruits on B16-F10 melanoma cells. Food Nutr. Res. 2017, 61, doi:10.1080/16546628.2017.1325308.

50. Gonçalves, A.C.; Bento, C.; Nunes, A.R.; Simões, M.; Alves, G.; Silva, L.R. Multitarget protection of Pterospartum tridentatum phenolic-rich extracts against a wide range of free radical species, antidiabetic activity and effects on human colon carcinoma (Caco-2) cells. J. Food Sci. 2020, 85, 4377-4388, doi:10.1111/1750-3841.15511.

51. Afsar, T.; Trembley, J.H.; Salomon, C.E.; Razak, S.; Khan, M.R.; Ahmed, K. Growth inhibition and apoptosis in cancer cells induced by polyphenolic compounds of Acacia hydaspica: Involvement of multiple signal transduction pathways. Sci. Rep. 2016, 23077, doi:10.1038/srep23077.

52. Xiao, T.; Luo, Z.; Guo, Z.; Wang, X.; Ding, M.; Wang, W.; Shen, X.; Zhao, Y. Multiple roles of black raspberry anthocyanins protecting against alcoholic liver disease. Molecules 2021, 26, 2313.

53. Vepsäläinen, S.; Koivisto, H.; Pekkarinen, E.; Mäkinen, P.; Dobson, G.; McDougall, G.J.; Stewart, D.; Haapasalo, A.; Karjalainen, R.O.; Tanila, H.; Hiltunen, M. Anthocyanin-enriched bilberry and blackcurrant extracts modulate amyloid precursor protein processing and alleviate behavioral abnormalities in the APP/PS1 mouse model of Alzheimer's disease. J. Nutr. Biochem. 2013, 24, 360-370, doi:10.1016/j.jnutbio.2012.07.006.

54. Gay, N.H.; Phopin, K.; Suwanjang, W.; Songtawee, N.; Ruankham, W. Neuroprotective effects of phenolic and carboxylic acids on oxidative stress-induced toxicity in human neuroblastoma SH-SY5Y cells. Neurochem. Res. 2018, 43, 619-636, doi:10.1007/s11064-017-2463-x.

55. Jiménez-aspee, F.; Theoduloz, C.; Neves, M.; Rodríguez-werner, M.A.; Schmalfuss, E.; Winterhalter, P.; Schmeda-hirschmann, G. Phenolics from the Patagonian currants Ribes spp.: Isolation, characterization and cytoprotective effect in human AGS cells. J. Funct. Foods 2016, 26, 11-26, doi:10.1016/j.jff.2016.06.036.

56. Ribera-Fonseca, A.; Jim, D.; Leal, P.; Riquelme, I.; Roa, J.C.; Alberdi, M.; Peek, R.M.; Reyes-Díaz, M. The anti-proliferative and anti-invasive effect of leaf extracts of blueberry plants treated with methyl jasmonate on human gastric cancer in vitro is related to their antioxidant properties. Antioxidants 2020, 9, 45.

57. Taciak, B.; Białasek, M.; Braniewska, A.; Sas, Z.; Sawicka, P.; Kiraga, Ł.; Rygiel, T.; Kro, M. Evaluation of phenotypic and functional stability of RAW 264.7 cell line through serial passages. PLoS One 2018, 13, e0198943.

58. Pereira, R.B.; Pereira, D.M.; Jim, C.; Rodr, J.; Nieto, R.M.; Videira, R.A.; Silva, O.; Andrade, P.B. Anti-inflammatory effects of $5 \alpha, 8 \alpha$-Epidioxycholest-6-en-3 $\beta$-ol, a steroidal endoperoxide isolated from Aplysia depilans, based on bioguided fractionation and NMR analysis. Mar. Drugs 2019, 17, 330. 